\title{
Efficacy of Root Zone Temperature Increase in Root and Shoot Development and Hormone Changes in Different Maize Genotypes
}

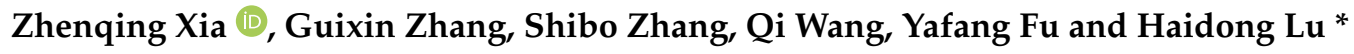 \\ College of Agronomy, Northwest A\&F University, Yangling 712100, China; 17854233612@163.com (Z.X.); \\ zgx199869@163.com (G.Z.); z2335570357@163.com (S.Z.); QiWangNwafu@163.com (Q.W.); \\ f13546632915@163.com (Y.F.) \\ * Correspondence: lhd2042@163.com; Tel.: +187-0079-1206
}

check for updates

Citation: Xia, Z.; Zhang, G.; Zhang, S.; Wang, Q.; Fu, Y.; Lu, H. Efficacy of Root Zone Temperature Increase in Root and Shoot Development and Hormone Changes in Different Maize Genotypes. Agriculture 2021, 11, 477. https://doi.org/10.3390/

agriculture11060477

Academic Editors: Mingcai Zhang and Urs Feller

Received: 24 March 2021

Accepted: 20 May 2021

Published: 22 May 2021

Publisher's Note: MDPI stays neutral with regard to jurisdictional claims in published maps and institutional affiliations.

Copyright: (c) 2021 by the authors. Licensee MDPI, Basel, Switzerland. This article is an open access article distributed under the terms and conditions of the Creative Commons Attribution (CC BY) license (https:/ / creativecommons.org/licenses/by/ $4.0 /)$.
Abstract: In the context of global warming, the effects of warming in the root zone of crops on maize seedling characteristics deserve research attention. Previous studies on the adaptive traits of dryland maize have mainly focused on soil moisture and nutrients, rather than analyzing potential factors for the adaptive traits of root zone warming. This study was conducted to investigate the effects of different root zone warming ranges on the agronomic traits, hormones, and microstructures of maize seedling roots and leaves. The results showed that minor increases in the root zone temperature significantly enhanced maize seedling growth. However, when the temperature in the root zone was excessive, the stem diameter, root surface area, root volume, total root length, dry matter accumulation, and root/shoot biomass of maize seedlings sharply decreased. Under high temperature stress in the root zone, the root conduit area; root stele diameter; root content of trans-zeatin (ZT), gibberellin $\mathrm{A}_{3}\left(\mathrm{GA}_{3}\right)$, and indoleacetic acid (IAA); leaf thickness; upper and lower epidermis thickness; and leaf content of $\mathrm{ZT}$ and $\mathrm{GA}_{3}$ were significantly decreased. The hormone content and microstructure changes might be an important reason for root growth maldevelopment and nutrient absorption blockage, and they also affected the leaf growth of maize seedlings. Compared with the 'senescent' maize type Shaandan 902 (SD902), the plant microstructure of the 'stay-green' maize type Shaandan 609 (SD609) was less affected by increased temperatures, and the ability of the root system to absorb and transport water was stronger, which might explain its tolerance of high temperature stress in the root zone.

Keywords: maize; root zone warmed; anatomical structure; hormone

\section{Introduction}

Global temperatures have risen rapidly over recent years, and the impact of temperature changes on crop growth and development has become a problem that cannot be ignored $[1,2]$. As the global warming trend continues to intensify, soil temperatures in the root zone of crops continue to change significantly [3]. Maize, as one of the most important food and feed crops in China, is of great significance to China's food security [4]. Due to the extensive application of plastic film in corn production, the trend of increasing soil temperature near the roots has increased [5]. White plastic film can increase the average daily temperature of surface soil by about $2{ }^{\circ} \mathrm{C}$, and the effect of warming is most obvious during the maize seedling stage [6].

The root system is an important organ that affects maize growth, and root growth affects nutrient and water absorption [7]. As a result of its direct contact with soil, the root system is more sensitive to the soil environment, and root growth and development have a strong correlation with the aboveground plant characteristics. Underground stress causes a series of physiological reactions in the root system, often affecting the plant height, leaf area, leaf structure, and content of hormones [8-11]. Although corn is a thermophilic crop, 
excessive heat can damage the normal function of corn and thus inhibit its growth. An increase in soil temperature by even $1{ }^{\circ} \mathrm{C}$ will have a huge impact on crop growth [12]. Soil temperature significantly affects the soil nutrient and water use efficiency of crops, which is the main limiting factor for crop productivity. Various biochemical processes in the soil are affected by soil temperature. When the soil temperature is high, organic matter decomposes quickly, but when the soil temperature is low, it decomposes slowly [13]. The activity of various enzymes and microorganisms in the soil is closely related to temperature [14]. There is a significant positive correlation between soil temperature and soil respiration rate, and temperature increases can increase the emissions of $\mathrm{CO}_{2}$ and $\mathrm{CH}_{4}$ from farmland [15]. An increase in soil temperature can also increase the solubility of some salts in the soil and, at the same time, weaken the adsorption of ions in the soil colloid, making it easier for them to be absorbed by crops [16]. The movement of soil water and form of soil water are also affected by soil temperature changes: When soil temperature rises, the viscosity and surface tension of soil water decreases, the permeability coefficient increases, and the rate of crop water absorption increases [17]. Soil temperature not only affects the water content of the soil, but also affects water use efficiency by crops. Araghi et al. [18] found that in the late stage of corn growth, if the soil temperature is too high, it significantly reduces the water use efficiency of corn, thereby affecting the yield. The activity of various enzymes in crop roots is also closely related to soil temperature. For example, in the case of root zone warming, root antioxidant enzyme activity and root vitality change significantly, affecting plant growth parameters and photosynthesis [19]. To date, most studies have indirectly analyzed the effect of soil temperature on corn through different mulching methods $[20,21]$. Research on the effect of root zone warming on the growth and anatomical structure of corn seedlings and its hormone regulation mechanism has not been reported.

In this study, the hydroponic method was adopted to simulate soil temperature change by adjusting the water temperature, which solved the problems of the interference of soil moisture on the test results and the uneven and unstable temperature increase in the traditional method. In this experiment, we investigated the effect of root zone warming treatment on the growth and development of the root canopy, the anatomy of root leaves, and the hormone content of maize seedlings. We attempted to reveal the response and adaptability of maize seedlings to warming of the root zone, with a view to providing a theoretical basis for the green and safe production of corn under the scenario of global warming and rising soil temperature.

\section{Materials and Methods}

\subsection{Experimental Treatments}

The maize materials used for the tests were the 'stay-green' maize type Shaandan 609 (SD609) and the 'senescent' maize type Shaandan 902 (SD902). These two varieties were bred by Northwest Agriculture and Forestry University and belonged to the cultivated varieties in this region. SD609 is a stay-green variety with a better stress resistance than SD902, which is a senescence variety with poor stress resistance. The two varieties have similar growth periods. The experimental materials were provided by the Key Laboratory of Maize Biology and Genetics and Breeding in the Northwest Arid Region of the Ministry of Agriculture.

The full and consistent corn seeds were sterilized with $70 \%$ ethanol for $5 \mathrm{~min}$ and soaked in distilled water for $12 \mathrm{~h}$. Subsequently, seeds were placed in a germination box for 2 days. Similar size seedlings were selected and planted in a plastic box $(40 \mathrm{~cm} \times 30 \mathrm{~cm} \times$ $12 \mathrm{~cm}$ ) containing $10 \mathrm{~L}$ of $1 / 2$ Hoagland nutrient solution. The nutrient solution consisted of the following: $\mathrm{Ca}\left(\mathrm{NO}_{3}\right)_{2}(2 \mathrm{mmol} / \mathrm{L}), \mathrm{MgSO}_{4} \cdot 7 \mathrm{H}_{2} \mathrm{O}(0.65 \mathrm{mmol} / \mathrm{L}), \mathrm{K}_{2} \mathrm{SO}_{4}(0.75 \mathrm{mmol} / \mathrm{L})$, $\mathrm{KCl}(0.1 \mathrm{mmol} / \mathrm{L}), \mathrm{MnSO}_{4} \cdot \mathrm{H}_{2} \mathrm{O}\left(1 \times 10^{-3} \mathrm{mmol} / \mathrm{L}\right), \mathrm{CuSO}_{4} \cdot 5 \mathrm{H}_{2} \mathrm{O}\left(1 \times 10^{-4} \mathrm{mmol} / \mathrm{L}\right)$, $\mathrm{ZnSO}_{4}\left(1 \times 10^{-3} \mathrm{mmol} / \mathrm{L}\right),\left(\mathrm{NH}_{4}\right)_{6} \mathrm{Mo}_{7} \mathrm{O}_{24}\left(5 \times 10^{-5} \mathrm{mmol} / \mathrm{L}\right)$, Fe-ethylene diamine tetraacetic acid $(0.01 \mathrm{mmol} / \mathrm{L})$, and $\mathrm{H}_{3} \mathrm{BO}_{3}\left(1 \times 10^{-3} \mathrm{mmol} / \mathrm{L}\right)$. There were a total of 24 seedlings per box, 3 treatments per variety, and 3 boxes per treatment, which were placed in a $24{ }^{\circ} \mathrm{C}$ culture room for cultivation. An air conditioner was used to control 
the temperature of the cultivation room, and a thermometer was used to monitor the room temperature in real time, with a temperature control accuracy of $\pm 0.5^{\circ} \mathrm{C}$. There was continuous ventilation with an electric air pump during the cultivation period. When the seedlings had grown to have one leaf and one heart, we put a variable frequency constant temperature heating rod (Zhongbao Ribao, Zhongshan, China, power $100 \mathrm{~W}$, temperature control accuracy $\pm 0.2{ }^{\circ} \mathrm{C}$ ) in the plastic box to enable a precise root zone temperature increase. The variable frequency constant temperature heating rod included water temperature heating equipment and a temperature probe that accurately controlled the water temperature and monitored the temperature in real time. In order to reduce the heat exchange between water and air, the plastic box was wrapped with sponge, the water surface was covered with perforated foam board, and the corn seedlings were passed through small holes and fixed with sponge. The experimental treatments were as follows: root zone medium-temperature treatment (constant temperature heating equipment kept water temperature at $30^{\circ} \mathrm{C}$ ), root zone high-temperature treatment (constant temperature heating equipment kept water temperature at $36^{\circ} \mathrm{C}$ ), control (temperature of root zone did not increase-temperature was held at $24^{\circ} \mathrm{C}$ ).

\subsection{Determination of Morphological Indicators}

After 8 days of root zone warming treatment, 3 seedlings were taken from each plot to determine the plant height, stem thickness, and leaf area; the leaf area was calculated by leaf area $=$ length $\times$ width $\times$ coefficient (expanded leaf: 0.75 , unexpanded leaf: 0.5$)$. The corn root system was scanned with an EPSON V800 scanner (Epson China Co. Ltd., Beijing, China), and Win RHIZO (Regent Instructions, Quebec, Canada) root system analysis software was used to analyze corn root surface area, root volume, total root length, and average root diameter. The corn seedlings were then placed in an oven at $105^{\circ} \mathrm{C}$ for $15 \mathrm{~min}$, after which the plants were dried to a constant weight at $80^{\circ} \mathrm{C}$, and we measured the dry matter mass above and below ground with an electronic balance. Root/shoot biomass (RSB, \%) was calculated according to the following equation:

$$
\mathrm{RSB}=\mathrm{RDW} /(\mathrm{SDW}+\mathrm{RDW}) \times 100 \%
$$

where RDW is root dry weight and SDW is the shoot dry weight in grams.

\subsection{Determination of the Microstructure of Root and Leaves}

After 8 days of root zone warming treatment, the last piece of unfolded leaf and the middle of the main root were taken and fixed with formalin-acetic acid-alcohol (FAA) fixing solution. They were then dehydrated with ethanol, treated with xylene, and embedded in paraffin. The thickness of the slice was $8 \mu \mathrm{m}$. Samples were then dyed with SafraninO-Fast Green staining to make a permanent film, observed under an OLYMPUSBX51 microscope (Olympus China Co., Ltd., Beijing, China), and photographed by Micro Publisher3.3RTV digital imaging system (QImaging, Surrey, BC, Canada). The Image-Pro Plus 6.0 software (Media Cybernetics, Rockville, MD, USA) was used to measure the diameter of the stele, thickness of the cortex, diameter of the conduit, thickness of the leaf, thickness of the upper epidermis, and thickness of the lower epidermis. For each indicator, 10 sets of data were measured to reduce error. We calculated the conduit area using the area formula of the circle $[22,23]$.

\subsection{Determination of Endogenous Hormone Content}

After 8 days of root zone warming treatment, $0.2 \mathrm{~g}$ of corn seedling roots and leaves were taken and the samples were extracted with $1.5 \mathrm{~mL}$ pr-cooled $80 \%$ methanol and extracted overnight at $4{ }^{\circ} \mathrm{C}$. The supernatant was collected and residue was extracted in $0.5 \mathrm{~mL}$ of $80 \%$ methanol for $2 \mathrm{~h}$. After centrifugation, the supernatant was collected and mixed with the first supernatant. The content of indoleacetic acid (IAA), gibberellin $\mathrm{A}_{3}$ $\left(\mathrm{GA}_{3}\right)$, and trans-zeatin $(\mathrm{ZT})$ was determined by high-performance liquid chromatography (HPLC) system. The sample was filtered through syringe filter, and $10 \mu \mathrm{L}$ was injected into 
Kromasil C18 reversed-phase column $(250 \mathrm{~mm} \times 4.6 \mathrm{~mm}, 5 \mu \mathrm{m}$; Agilent, Palo Aito, CA, USA). The $\mathrm{GA}_{3}$ and IAA were eluted isocratically in the mobile phase with $1 \%$ acetic acid and $100 \%$ methanol $(3: 2, \mathrm{v} / \mathrm{v})$ at a flow rate of $1 \mathrm{~mL} \mathrm{~min}^{-1}$, and they were measured at $254 \mathrm{~nm}$ and $30{ }^{\circ} \mathrm{C}$. The ZT was eluted isocratically in the mobile phase with water and $100 \%$ methanol $(7: 3, \mathrm{v} / \mathrm{v})$ at a flow rate of $1 \mathrm{~mL} \mathrm{~min}^{-1}$, and it was measured at $270 \mathrm{~nm}$ and $30{ }^{\circ} \mathrm{C}[24]$.

\subsection{Statistical Analysis}

Significance and Duncan's tests were performed using SPSS 20.0 (SPSS; Chicago, IL, USA). Differences were judged by the least significant differences test using a 0.05 level of significance. Origin2017 (OriginLab, Northampton, MA, USA) software was used for drawing.

\section{Results}

\subsection{Effects of Different Root Zone Temperatures on Root-Shoot Dry Matter Accumulation and Root/Shoot Biomass of Different Maize Genotypes}

The accumulation of dry matter in SD609 and SD902 roots and aboveground biomass was significantly different compared with the control under different root zone warming treatments (Figure 1). As the temperature in the root zone increased, the root dry weight and aboveground dry weight of the two maize varieties increased first and then decreased. Under the root zone medium-temperature treatment (MT), the root dry weight and aboveground dry weight of the two maize varieties were significantly increased; the difference between the varieties was not significant. Under the root zone high-temperature treatment (HT), the dry weight of SD609 roots and aboveground biomass decreased by $29.17 \%$ and $18.39 \%(p<0.05)$, respectively, and the dry weight of SD902 roots and aboveground biomass decreased by $57.78 \%$ and $39.61 \%(p<0.05)$, respectively. The dry weight of SD609 roots and aboveground biomass under the HT treatment was significantly higher than that of SD902 $(p<0.05)$. As the root zone temperature increased, the root/shoot biomass of the two maize varieties increased at first but then decreased. The root/shoot biomass of the two maize varieties increased significantly under the MT treatment. Compared with the control, the root/shoot biomass of SD609 and SD902 was increased by $17.90 \%$ and $35.12 \%$ $(p<0.05)$, respectively. Under the HT treatment, the root/shoot biomass of SD902 was significantly reduced by $28.28 \%(p<0.05)$, and the root/shoot biomass of SD609 was not significantly difference between the HT treatment and the control.

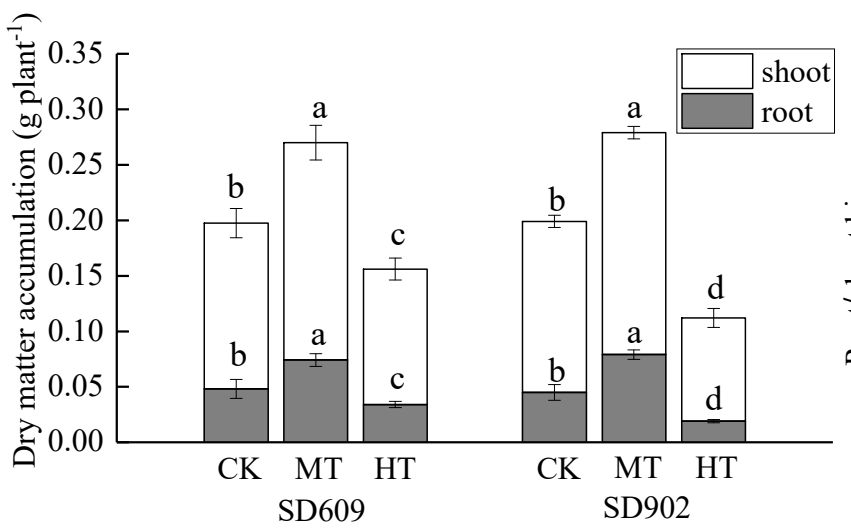

Maize cultivars

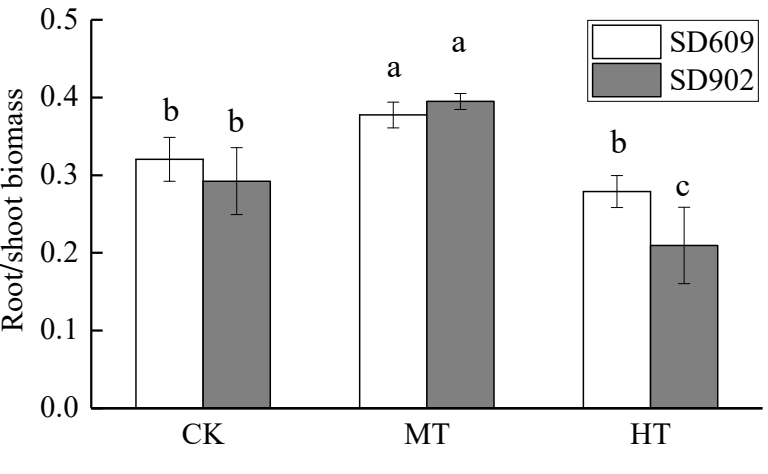

Treatments

Figure 1. Effects of different root zone temperatures on dry matter accumulation and root/shoot biomass of SD609 and SD902. root zone normal-temperature treatment (CK): $24^{\circ} \mathrm{C}$, root zone medium-temperature treatment (MT): $30{ }^{\circ} \mathrm{C}$, root zone high-temperature treatment $(\mathrm{HT}): 36{ }^{\circ} \mathrm{C}$ (root zone temperature). Notations above bars of $\mathrm{a}, \mathrm{b}, \mathrm{c}$, and $\mathrm{d}$ indicate homogeneous groups $(\alpha=0.05)$. 


\subsection{Effects of Different Root Zone Temperatures on Root Architecture and Anatomical Structure of Different Maize Genotypes}

\subsubsection{Root Surface Area, Root Volume, and Total Root Length}

As the root zone temperature increased, the root surface area, root volume, and total root length of the two maize varieties increased at first but then decreased, and all of them were highest under the MT treatment and lowest under the HT treatment (Figure 2). The root surface area, root volume, and total root length of SD609 and SD902 were significantly increased under the MT treatment. Under the HT treatment, the root surface area, root volume, and total root length of the two corn varieties decreased by $48.98 \%, 53.95 \%$, and $35.42 \%$ in SD609 $(p<0.05)$, respectively, while they decreased by $69.07 \%, 72.29 \%$, and $58.61 \%$ in SD902 $(p<0.05)$, respectively. The surface area and total root length of SD609 root under the HT treatment were significantly higher than those of SD902 $(p<0.05)$.
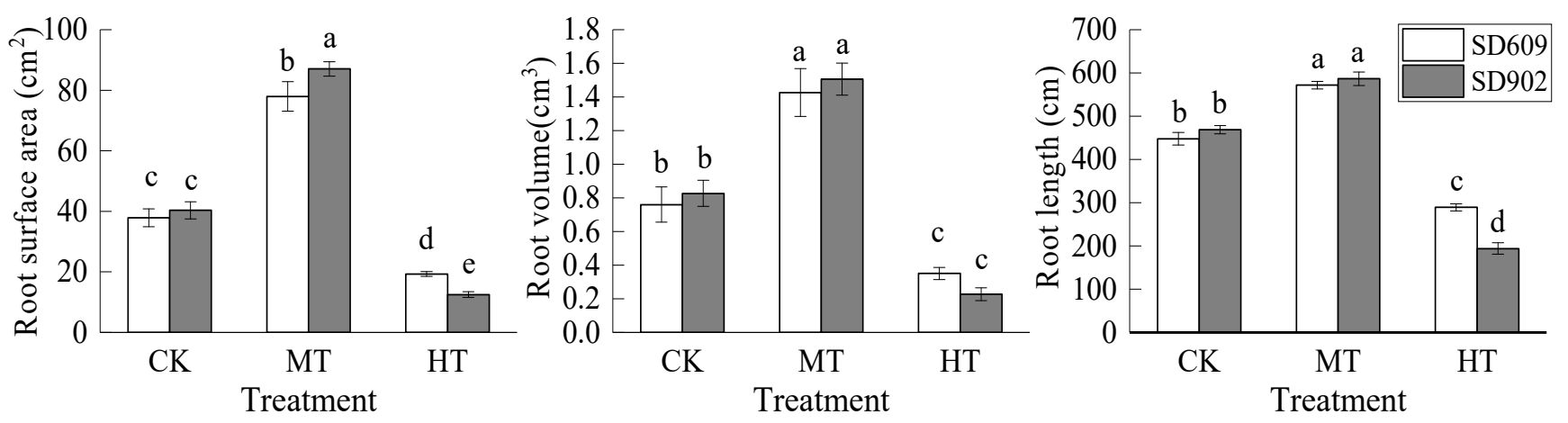

Figure 2. Effects of different root zone temperatures on root surface area, root volume, and root length of SD609 and SD902 maize varieties. CK: $24{ }^{\circ} \mathrm{C}$, MT: $30{ }^{\circ} \mathrm{C}, \mathrm{HT}: 36^{\circ} \mathrm{C}$ (root zone temperature). Notations above bars of a, b, $\mathrm{c}, \mathrm{d}$ and e indicate homogeneous groups $(\alpha=0.05)$.

\subsubsection{Root Anatomical Structure}

It can be seen from Table 1 and Figure 3 that under different root zone warming treatments, the root microstructure of each treatment was significantly different. Under the MT treatment, the conduit area and the stele diameter were increased significantly $(p<0.05)$, while under the HT treatment, the conduit area and the stele diameter of the two corn varieties decreased significantly-for SD609 they decreased by $7.66 \%$ and $4.98 \%$, respectively, and for SD902 they decreased by $17.22 \%$ and $13.77 \%$, respectively $(p<0.05)$. The average conduit area of SD902 under the HT treatment was significantly reduced, and some of the conduit walls were deformed, which may have affected the water absorption performance of the root system. The root zone warming treatment also affected the thickness of the root cortex. With increasing root zone temperature, the root cortex thickness of SD609 corn seedlings decreased first and then increased, but the difference between the warming treatment and CK was not significant. The root thickness of SD902 under the HT treatment was significantly higher than those of the CK and MT treatments $(p<0.05)$. 
Table 1. Effect of different root zone temperatures on the root microstructure of SD609 and SD902.

\begin{tabular}{ccccc}
\hline Cultivar & Treatment & $\begin{array}{c}\text { Conduit Area } \\
\left(\boldsymbol{\mu \mathbf { m } ^ { 2 } )}\right.\end{array}$ & $\begin{array}{c}\text { Stele Diameter } \\
(\boldsymbol{\mu m})\end{array}$ & $\begin{array}{c}\text { Cortex } \\
\text { Thickness }(\boldsymbol{\mu m})\end{array}$ \\
\hline SD609 & CK & $28155.61 \pm 1142.63 \mathrm{~b}$ & $546.31 \pm 5.54 \mathrm{~b}$ & $327.83 \pm 5.87 \mathrm{bc}$ \\
& MT & $32324.04 \pm 446.43 \mathrm{a}$ & $580.53 \pm 3.06 \mathrm{a}$ & $312.34 \pm 5.17 \mathrm{c}$ \\
& HT & $25999.20 \pm 642.11 \mathrm{c}$ & $519.09 \pm 7.45 \mathrm{c}$ & $338.68 \pm 4.23 \mathrm{ab}$ \\
SD902 & CK & $29084.10 \pm 737.56 \mathrm{~b}$ & $557.83 \pm 4.96 \mathrm{~b}$ & $330.59 \pm 8.40 \mathrm{bc}$ \\
& MT & $33280.72 \pm 543.33 \mathrm{a}$ & $586.98 \pm 6.56 \mathrm{a}$ & $319.92 \pm 2.27 \mathrm{c}$ \\
& HT & $24076.32 \pm 105.56 \mathrm{~d}$ & $481.01 \pm 7.52 \mathrm{~d}$ & $351.16 \pm 11.97 \mathrm{a}$ \\
\hline
\end{tabular}

Note: root zone normal-temperature treatment (CK): $24^{\circ} \mathrm{C}$, root zone medium-temperature treatment (MT): $30^{\circ} \mathrm{C}$, root zone high-temperature treatment $(\mathrm{HT}): 36^{\circ} \mathrm{C}$ (root zone temperature). Notations of $\mathrm{a}, \mathrm{b}, \mathrm{c}$, and dindicate homogeneous groups $(\alpha=0.05)$.

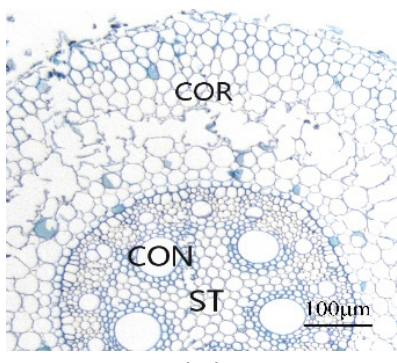

(A)

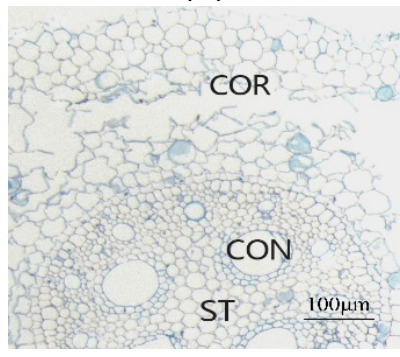

(D)

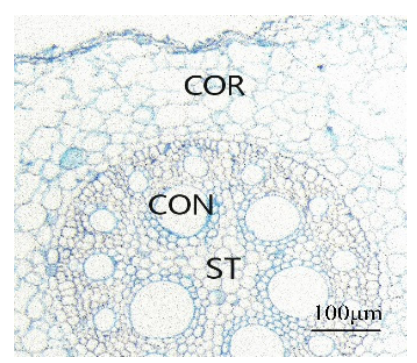

(B)

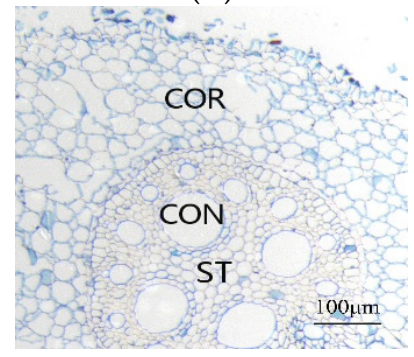

(E)

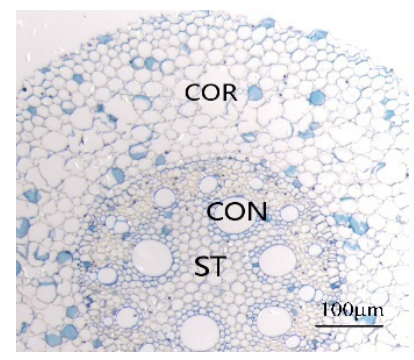

(C)

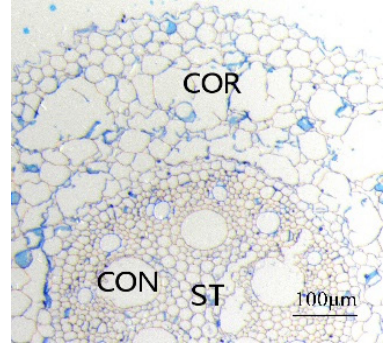

(F)

Figure 3. Effects of different root zone temperatures on the root microstructure of SD609 and SD902. (A) SD609 CK, (B) SD609 MT, (C) SD609 HT, (D) SD902 CK, (E) SD902 MT, (F) SD902 HT. CK: $24^{\circ}$ C, MT: $30{ }^{\circ} \mathrm{C}, \mathrm{HT}: 36^{\circ} \mathrm{C}$ (root zone temperature). CON—conduit, ST—stele, COR-cortex.

3.3. Effects of Different Root Zone Temperatures on Growth of the Stem and Leaf and the Leaf Anatomical Structure of Different Maize Genotypes

\subsubsection{Plant Height, Stem Diameter, and Leaf Area}

It can be seen in Figure 4 that the seedling height, stem diameter, and leaf area of the two maize varieties first increased and then decreased under the root warming treatment. Under the MT treatment, the plant height, stem diameter, and leaf area per plant of maize seedlings increased significantly-for SD609, the plant height, stem diameter, and leaf area per plant were increased by $31.53 \%, 24.29 \%$, and $35.93 \%(p<0.05)$, respectively, while for SD902 they increased by 34.11\%, 23.69\%, and 34.69\% $(p<0.05)$, respectively. High temperature treatment in the root zone significantly reduced the stem thickness of SD609 and the stem diameter and leaf area per plant of SD902 $(p<0.05)$. Comparatively, the plant height was not significantly affected by the high temperature. 

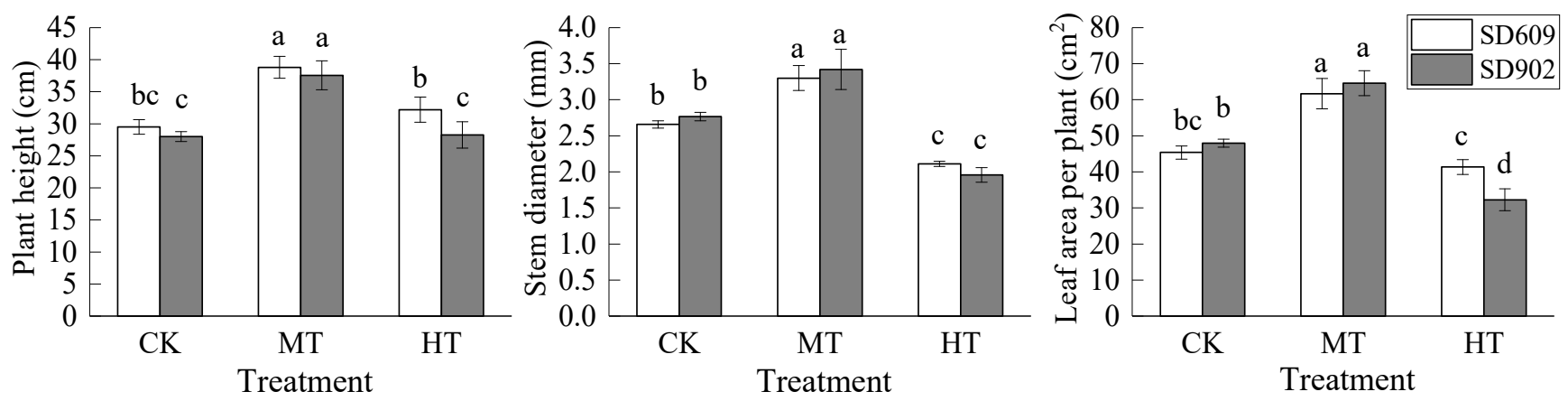

Figure 4. Effects of different root zone temperatures on plant height, stem diameter, and leaf area of SD609 and SD902. CK: $24{ }^{\circ} \mathrm{C}$, MT: $30^{\circ} \mathrm{C}, \mathrm{HT}: 36^{\circ} \mathrm{C}$ (root zone temperature). Notations above bars of a, b, c, d indicate homogeneous groups $(\alpha=0.05)$.

\subsubsection{Leaf Anatomical Structure}

The root zone warming treatment had a significant effect on the thickness of maize seedling leaves and the thickness of the upper and lower epidermis (Table 2). The root zone medium temperature treatment significantly increased the leaf thickness and upper epidermal thickness. Under the high temperature treatment of the root zone, the leaf thickness and upper and lower epidermis thickness were decreased significantly compared with the control-for SD609, they decreased by $24.92 \%, 20.36 \%$, and $17.92 \%$, respectively, and for SD902, they decreased by $26.75 \%, 29.07 \%$, and $31.43 \%$, respectively $(p<0.05)$. The high temperature environment in the root zone had a greater influence on the leaf microstructure of SD902. Figure 5 shows that under the MT treatment, the maize seedling leaves had a greater volume of Kranz structures, and the arrangement of mesophyll cells of the CK and MT treatments was relatively neat. The number of mesophyll cells was smaller under the HT treatment, and the arrangement of mesophyll cells was irregular.

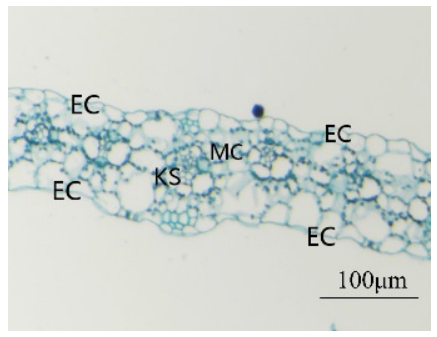

(A)

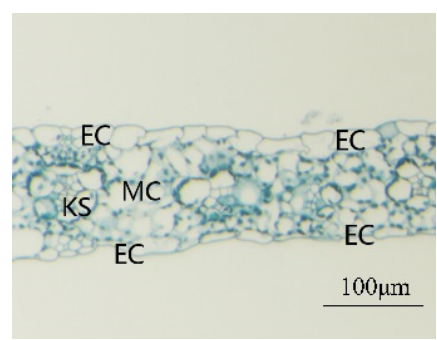

(D)

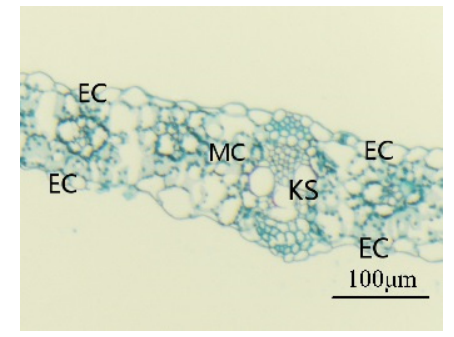

(B)

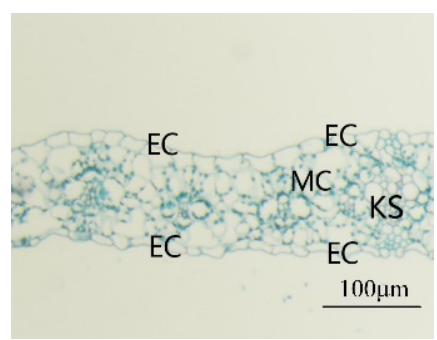

(E)

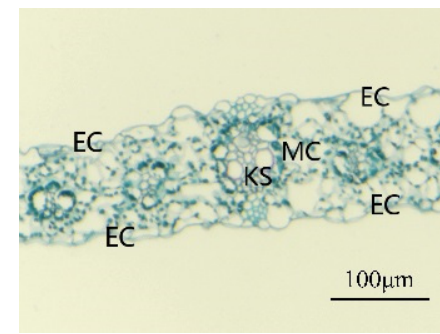

(C)

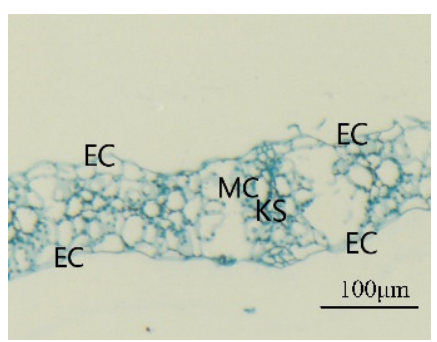

(F)

Figure 5. Effects of different root zone temperatures on the leaf microstructure of SD609 and SD902. (A) SD609 CK, (B) SD609 MT, (C) SD609 HT, (D) SD902 CK, (E) SD902 MT, (F) SD902HT. CK: $24{ }^{\circ} \mathrm{C}, \mathrm{MT}: 30{ }^{\circ} \mathrm{C}, \mathrm{HT}: 36^{\circ} \mathrm{C}$ (root zone temperature). EC—epidermis cell, MC—-mesophyll cell, KS—Kranz structures. 
Table 2. Effects of different root zone temperatures on the leaf microstructure of SD609 and SD902.

\begin{tabular}{ccccc}
\hline Cultivar & Treatment & $\begin{array}{c}\text { Leaf } \\
\text { Thickness }(\boldsymbol{\mu m})\end{array}$ & $\begin{array}{c}\text { Upper Epidermis } \\
\text { Thickness }(\boldsymbol{\mu m})\end{array}$ & $\begin{array}{c}\text { Lower Epidermis } \\
\text { Thickness }(\boldsymbol{\mu m})\end{array}$ \\
\hline SD609 & CK & $127.99 \pm 1.68 \mathrm{~b}$ & $16.45 \pm 0.52 \mathrm{~b}$ & $10.10 \pm 0.19 \mathrm{~b}$ \\
& MT & $152.20 \pm 3.63 \mathrm{a}$ & $23.27 \pm 1.00 \mathrm{a}$ & $11.03 \pm 0.48 \mathrm{ab}$ \\
SD902 & HT & $96.10 \pm 2.18 \mathrm{~d}$ & $13.10 \pm 0.84 \mathrm{c}$ & $8.29 \pm 0.56 \mathrm{c}$ \\
& CK & $118.94 \pm 2.33 \mathrm{c}$ & $15.34 \pm 0.78 \mathrm{~b}$ & $10.31 \pm 0.26 \mathrm{~b}$ \\
& MT & $145.76 \pm 4.53 \mathrm{a}$ & $21.84 \pm 0.21 \mathrm{a}$ & $11.69 \pm 0.45 \mathrm{a}$ \\
& HT & $87.12 \pm 2.45 \mathrm{e}$ & $10.88 \pm 0.69 \mathrm{~d}$ & $7.07 \pm 0.35 \mathrm{~d}$ \\
\hline
\end{tabular}

Note: CK: $24{ }^{\circ} \mathrm{C}, \mathrm{MT}: 30^{\circ} \mathrm{C}, \mathrm{HT}: 36^{\circ} \mathrm{C}$ (root zone temperature). Notations of a, b, c, d and e indicate homogeneous groups $(\alpha=0.05)$.

\subsection{Effects of Different Root Zone Temperatures on Root-Shoot Hormone Contents of Different Maize Genotypes}

3.4.1. $\mathrm{ZT}, \mathrm{GA}_{3}$, and IAA Content in Root System

The contents of $\mathrm{ZT}, \mathrm{GA}_{3}$, and IAA in the roots of the two corn varieties increased and then decreased as the root zone temperature increased (Figure 6). Under the MT treatment, the contents of $\mathrm{ZT}, \mathrm{GA}_{3}$, and IAA in the roots of maize seedlings increased by different degrees: the contents of $\mathrm{ZT}, \mathrm{GA}_{3}$, and IAA in the SD902 variety increased significantly $(p<0.05)$, while the contents of various hormones in SD609 were not significantly different from those in the $\mathrm{CK}$ treatment. The root hormone contents of the two varieties decreased significantly under the HT treatment: the contents of ZT, GA 3 , and IAA in SD609 plants decreased by $38.27 \%, 33.91 \%$, and $25.78 \%$, respectively $(p<0.05)$, while in SD902 plants, they decreased by $50.05 \%, 49.77 \%$, and $25.34 \%$, respectively $(p<0.05)$.
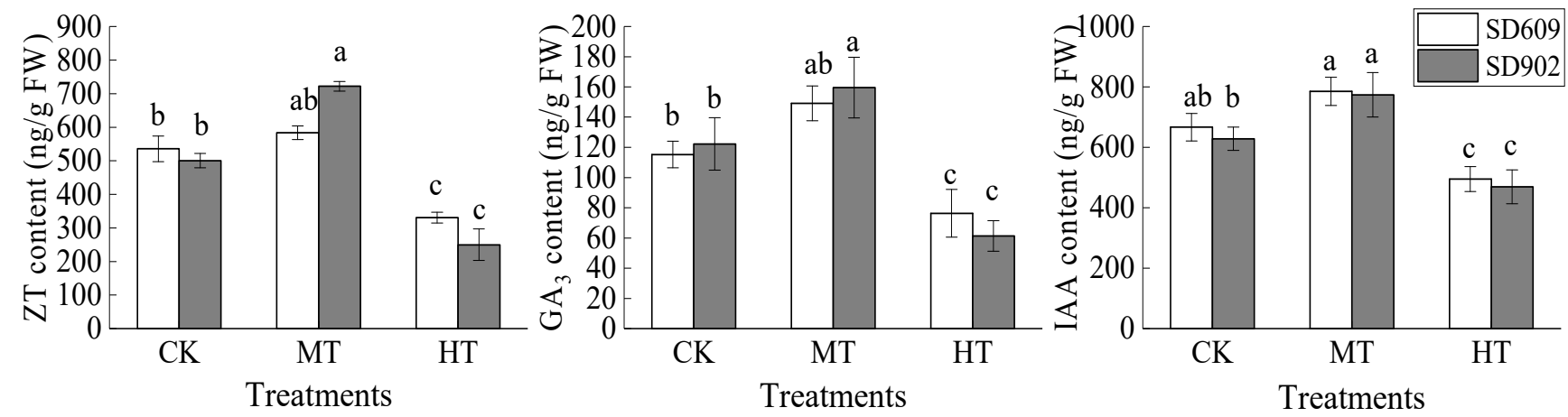

Figure 6. Effects of different root zone temperatures on root hormone contents of SD609 and SD902. CK: $24{ }^{\circ} \mathrm{C}, \mathrm{MT}: 30^{\circ} \mathrm{C}$, HT: $36{ }^{\circ} \mathrm{C}$ (root zone temperature). Notations above bars of $\mathrm{a}, \mathrm{b}, \mathrm{c}$, and d indicate homogeneous groups $(\alpha=0.05)$.

\subsection{2. $\mathrm{ZT}, \mathrm{GA}_{3}$, and IAA Content in Leaves}

As the temperature increased during the root zone warming treatment, the change trend of $\mathrm{ZT}, \mathrm{GA}_{3}$, and IAA contents in the leaves of the two maize varieties was similar to that of the root system (Figure 7). The contents of $Z \mathrm{~T}$ and $\mathrm{GA}_{3}$ in SD609 leaves and the contents of $\mathrm{ZT}, \mathrm{GA}_{3}$, and IAA in SD902 leaves were significantly increased under the MT treatment. However, under the HT treatment, the contents of $\mathrm{ZT}$ and $\mathrm{GA}_{3}$ in the leaves of SD609 plants were decreased by $48.77 \%$ and $54.64 \%$, respectively $(p<0.05)$, and in SD902 plants were decreased by $58.88 \%$ and $54.61 \%$, respectively $(p<0.05)$. There was no significant difference in leaf IAA content under the HT treatment compared with the CK treatment $(p<0.05)$. 

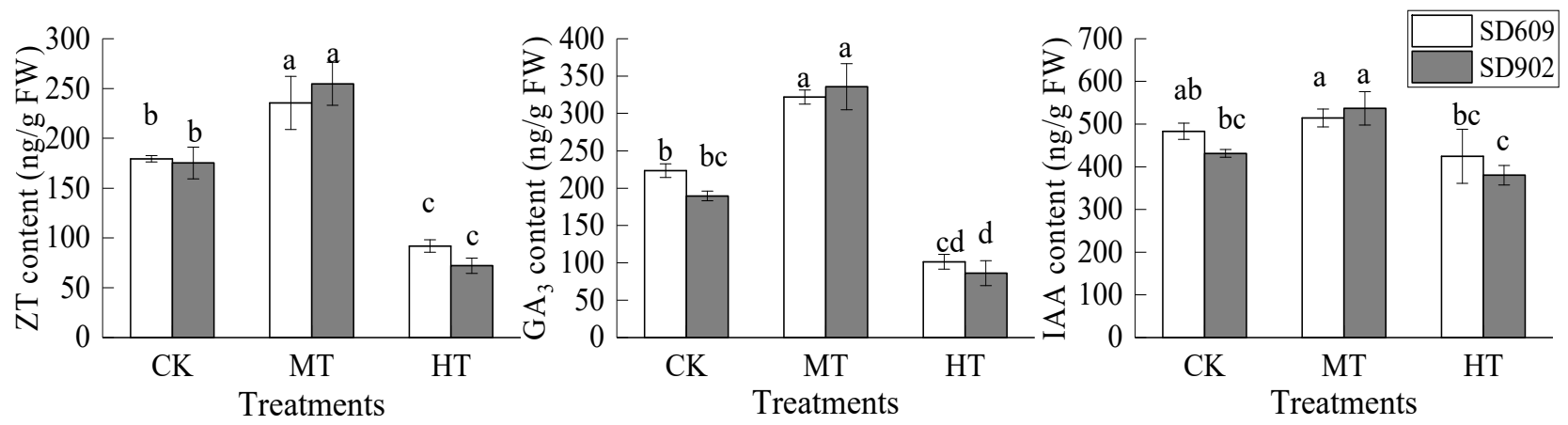

Figure 7. Effects of different root zone temperatures on the leaf hormone contents of SD609 and SD902. CK: $24{ }^{\circ} \mathrm{C}, \mathrm{MT}$ : $30{ }^{\circ} \mathrm{C}, \mathrm{HT}: 36^{\circ} \mathrm{C}$ (root zone temperature). Notations of a, b, c, and d above bars indicate homogeneous groups $(\alpha=0.05)$.

\section{Discussion}

The growth and development of crops at the seedling stage has an important impact on the stress resistance and yield formation in the later stage of crop growth. Environmental factors, such as light, moisture, and temperature, can affect the growth of crop seedlings. Here, it was found that the dry matter accumulation in the roots and shoots of maize seedlings was significantly associated with the root zone temperature. Increasing the root zone temperature was beneficial to the dry matter accumulation of maize seedlings, but when the temperature in the root zone was too high, the dry matter accumulation decreased rapidly. The change in root dry matter accumulation was larger than that of aboveground biomass under the warming treatment of the root zone. The dry matter accumulation of senescent maize varieties SD902 decreased significantly under high temperature stress in the root zone. Lu et al. [6] reported that the root dry matter accumulation and root volume of maize were decreased under excessively high soil temperatures. In another study, Sabri et al. [25] found that, in a warm climate, appropriately lowering the soil temperature can increase the total root mass of lettuce by $26-38 \%$. In this study, we found that under $30{ }^{\circ} \mathrm{C}$ root zone medium temperature conditions, the plant height, stem thickness, leaf area, root surface area, root volume, and total root length of maize seedlings were increased significantly $(p<0.05)$. However, under high temperature stress $\left(36^{\circ} \mathrm{C}\right)$ in the root zone, the stem diameter, root surface area, root volume, and total root length of maize seedlings were decreased significantly $(p<0.05)$. The root surface area and total root length of SD609 plants under high temperature stress were significantly higher than those of SD902 plants. Our results showed that the root zone temperature had a great influence on various morphological parameters of the maize seedling root system. Moderately increasing the root zone temperature during the corn seedling stage was beneficial to growth. However, excessively high temperature stress in the root zone reduced the root surface area, root volume, and total length of the root system and inhibited the absorption of water and nutrients by the corn seedlings, thus affecting the aboveground growth [26], and this effect was weaker in the stay-green maize type SD609 than the senescent type SD902.

The root/shoot biomass is an important indicator of plant health, reflecting the correlation between underground and aboveground parts of plants. Over recent decades, root/shoot biomass has received increasing attention as a sensitive index of plant stress induced by chemical or physical factors [27]. Stratopoulos et al. [28] indicated that increasing the root/shoot biomass can reduce the sensitivity of plants to drought. Under drought stress, plant biomass decreases, and root/shoot biomass increases $[29,30]$. We found that if the root zone temperature was increased moderately, the root/shoot biomass of maize seedlings increased significantly, but with high temperatures in the root zone, the senescent type SD902 root/shoot biomass was decreased significantly, while the SD609 root/shoot biomass was affected to a lesser extent. Therefore, we propose that the high root zone temperature significantly inhibits root growth during the seedling stage and may reduce 
the drought resistance of corn in the later stage. The stay-green maize type SD609 could maintain the coordinated growth of the root and shoot.

The growth environment of maize roots affects the microstructure of maize roots and leaves, and changes in the microstructure will significantly affect corn material transport and information transmission and can impact plant growth and development [31]. Studies have shown that the areas of the root column and the duct of the plant roots are significantly negatively correlated with local precipitation rates, and the plant will respond to water stress by changing the duct area [32]. In this experiment, the conduit area and stele diameter were significantly increased and the thickness of the cortex was decreased when the root region temperature was increased moderately. However, when the temperature in the root zone was excessive, the conduit area and stele diameter were decreased and the thickness of the cortex was increased. In addition, part of the duct wall of the senescent maize type SD902 under high temperature stress in the root zone was deformed, which reduced the absorption and transportation performance of the maize seedling root system, which may explain why high temperature stress in the root zone affects aboveground growth. It has been shown that there is a strong correlation between the growth and development of the aboveground and underground parts of plants $[33,34]$. In this experiment, warming of the root zone also had a significant effect on the microstructure of the leaves. As the root zone temperature increased, the leaf thickness, upper epidermis thickness, and lower epidermis thickness of maize seedlings showed an increasing trend followed by a decline. At excessively high root zone temperatures, the leaf thickness of the two varieties of maize seedlings and the thickness of the upper and lower epidermis were significantly reduced, the volume of the rosette structure was reduced, the number of mesophyll cells was reduced, and the arrangement of mesophyll cells and epidermal cells was irregular. This might be due to the decrease in the ability of the maize seedling roots to absorb and transport water under high temperature stress in the root zone, resulting in the loss of water in the leaves and therefore affecting the leaf microstructure. At the same time, Kranz structures in the leaves are the main component of high-efficiency photosynthesis in maize $[35,36]$, and the decrease in the volume of the wreath structure might be the internal reason for the significant decrease in dry matter content of maize seedlings under high temperature conditions in the root zone.

Phytohormones are produced by the plant's own metabolism and can be transported to various parts of the plant for information exchange. Thus, they play an important regulatory role in plant growth and development. Phytohormones respond quickly to abiotic stress and play a crucial role in plant physiological processes during adaptation to adverse environments [37]. A high temperature environment can significantly affect the synthesis, signal transduction, and polar transport of plant hormones [38,39]. Previous studies have shown that the content of IAA, CTK, and Z will decrease under high temperature stress $[38,39]$. In this study, we found that a moderate increase in the root zone temperature led to an increase in the contents of $\mathrm{ZT}, \mathrm{GA}_{3}$, and IAA in the roots and leaves of maize seedlings, but at an excessively high temperature in the root zone of $36^{\circ} \mathrm{C}$, the hormone content decreased significantly. Under root zone warming treatment, the changes in ZT and $\mathrm{GA}_{3}$ content were significantly greater than those in IAA. On the one hand, it may be that $\mathrm{ZT}$ and $\mathrm{GA}_{3}$ are more sensitive to temperature changes during the seedling stage of maize [38,39]. On the other hand, $\mathrm{ZT}$ and $\mathrm{GA}_{3}$ are mainly synthesized in the root system, while IAA is mainly synthesized in the shoots [40], and root zone warming directly affects the root system, so it is likely to have a greater impact on the synthesis of ZT and $\mathrm{GA}_{3}$. The microstructure of plants has a strong correlation with hormone content. Plant transport tissue is an important pathway for most plant hormones such as auxin, gibberellin, and cytokinin. Damage to the transport tissue will affect the transport of plant hormones, and plant hormones can also affect the development of plant xylem and phloem [40]. We come to similar conclusions based on the findings of this experiment. The variation in the change in IAA content in the roots was greater than in the leaves, while the variation of change in $\mathrm{ZT}$ and $\mathrm{GA}_{3}$ content was smaller in the roots than in the leaves. It is possible that the 
transporting tissue affects the downward transport of IAA synthesized from the ground and the upward transport of $\mathrm{ZT}$ and $\mathrm{GA}_{3}$ synthesized from the root system. At the same time, the changes in the content of hormones $\mathrm{ZT}$ and $\mathrm{GA}_{3}$ under increasing root zone temperatures may be an important reason for the changes in the microstructure of the roots and leaves of maize seedlings. The synergistic effect of multiple hormones $\left(\mathrm{ZT}, \mathrm{GA}_{3}\right.$, and IAA) can significantly affect crop dry matter accumulation and yield formation [41]. In this study, ZT, GA 3 , and IAA were significantly reduced under high temperature treatment in the root zone, which may be an important reason for the obstructed root and shoot development of maize seedlings and the rapid decline in dry matter content.

\section{Conclusions}

Root zone temperature significantly affects the root-shoot development of maize at the seedling stage. A moderate increase in the root zone temperature is beneficial for the growth of maize at the seedling stage and increases the root/shoot biomass. An excessive root zone temperature will reduce the contents of $Z \mathrm{~T}, \mathrm{GA}_{3}$, and IAA in corn roots and leaves; reduce the root conduit area and root stele diameter; increase the cortex thickness; and significantly reduce the leaf thickness, upper epidermis thickness, lower epidermis thickness, volume of Kranz structures, and root/shoot biomass. Compared with the senescent maize type, the stay-green maize type has better adaptability to high root zone temperatures.

Author Contributions: Investigation, Z.X., G.Z., S.Z., Q.W., and Y.F.; writing-original draft preparation, Z.X.; writing-review and editing, H.L. All authors have read and agreed to the published version of the manuscript.

Funding: This research was funded by the Natural Science Fund of China (grant number 31771724), and the APC was funded by the Natural Science Fund of China.

Institutional Review Board Statement: Not applicable.

Data Availability Statement: The data presented in this study are available on request from the corresponding author.

Acknowledgments: We thank all of the teachers and the team of the Key Laboratory of Maize Biology and Genetics and Breeding in the Northwest Arid Region of the Ministry of Agriculture for their support and help with the experiment.

Conflicts of Interest: The authors declare no conflict of interest.

\section{References}

1. Wang, N.; Wang, E.L.; Wang, J.; Zhang, J.P.; Zheng, B.R.; Huang, Y.; Tan, M.X. Modelling maize phenology, biomass growth and yield under contrasting temperature conditions. Agric. For. Meteorol. 2018, 250, 319-329. [CrossRef]

2. Xu, X.; Wang, L.; Sun, D.; Liu, L.; Banson, K.E. The Impact of Climate Change on Yield Potential of Maize across China. Int. J. Plant Prod. 2017, 11, 47-63.

3. Grillakis, M.G.; Koutroulis, A.G.; Papadimitriou, L.V.; Daliakopoulos, I.N.; Tsanis, I.K. Climate-Induced Shifts in Global Soil Temperature Regimes. Soil Sci. 2016, 181, 264-272. [CrossRef]

4. Gao, H.H.; Yan, C.R.; Liu, Q.; Li, Z.; Yang, X.; Qi, R.M. Exploring optimal soil mulching to enhance yield and water use efficiency in maize cropping in China: A meta-analysis. Agric. Water Manag. 2019, 225, 105741. [CrossRef]

5. Ma, Q.J.; Li, X.G.; Song, W.Y.; Jia, B.; Zhang, Q.; Lin, L.M.; Li, F.M. Plastic-film mulch and fertilization rate affect the fate of urea-N-15 in maize production. Nutr. Cycl. Agroecosyst. 2018, 112, 403-416. [CrossRef]

6. Lu, H.D.; Xia, Z.Q.; Fu, Y.F.; Wang, Q.; Xue, J.Q.; Chu, J. Response of Soil Temperature, Moisture, and Spring Maize (Zea mays L.) Root/Shoot Growth to Different Mulching Materials in Semi-Arid Areas of Northwest China. Agronomy 2020, 10, 453. [CrossRef]

7. Ma, L.S.; Li, Y.J.; Wu, P.T.; Zhao, X.N.; Chen, X.L.; Gao, X.D. Effects of varied water regimes on root development and its relations with soil water under wheat/maize intercropping system. Plant Soil 2019, 439, 113-130. [CrossRef]

8. Guo, E.L.; Liu, X.P.; Zhang, J.Q.; Wang, Y.F.; Wang, C.L.; Wang, R.; Li, D.J. Assessing spatiotemporal variation of drought and its impact on maize yield in Northeast China. J. Hydrol. 2017, 553, 231-247. [CrossRef]

9. Yan, W.M.; Zhong, Y.; Shangguan, Z.P. Evaluation of physiological traits of summer maize under drought stress. Soil Plant Sci. 2016, 66, 133-140. [CrossRef]

10. Zhang, H.L.; Yuan, C.; Mao, G.L.; Gao, X.; Zhu, L.; Xu, X. Evaluation of saline-alkali and drought tolerance in maize varieties. Bangladesh J. Botany 2019, 48, 1047-1063. [CrossRef] 
11. Chen, J.N.; Nolan, T.M.; Ye, H.X.; Zhang, M.C.; Tong, H.N.; Xin, P.Y.; Chu, J.F.; Chu, C.C.; Li, Z.H.; Yin, Y.H. Arabidopsis WRKY46, WRKY54, and WRKY70 Transcription Factors Are Involved in Brassinosteroid-Regulated Plant Growth and Drought Responses. Plant Cell 2017, 29, 1425-1439. [CrossRef] [PubMed]

12. Yin, W.; Chai, Q.; Guo, Y.; Fan, Z.L.; Hu, F.L.; Fan, H.; Zhao, C.; Yu, A.Z.; Coulter, J.A. Straw and plastic management regulate air-soil temperature amplitude and wetting-drying alternation in soil to promote intercrop productivity in arid regions. Field Crop. Res. 2020, 249, 107758. [CrossRef]

13. Robinson, J.M.; Barker, S.L.L.; Arcus, V.L.; McNally, S.R.; Schipper, L.A. Contrasting temperature responses of soil respiration derived from soil organic matter and added plant litter. Biogeochemistry 2020, 150, 45-59. [CrossRef]

14. Behtari, B.; Jafarian, Z.; Alikhani, H. Temperature sensitivity of soil organic matter decomposition in response to land management in semi-arid rangelands of Iran. Catena 2019, 179, 210-219. [CrossRef]

15. Chen, H.Y.; Zhu, T.; Li, B.; Fang, C.M.; Nie, M. The thermal response of soil microbial methanogenesis decreases in magnitude with changing temperature. Nat. Commun. 2020, 11, 1-7. [CrossRef]

16. Lenka, S.; Trivedi, P.; Singh, B.; Singh, B.P.; Pendall, E.; Bass, A.; Lenka, N.K. Effect of crop residue addition on soil organic carbon priming as influenced by temperature and soil properties. Geoderma 2019, 374, 70-79. [CrossRef]

17. Singh, J.; Maurya, I.B. Effect of black polythene mulch on growth and yield of winter dawn strawberry (Fragaria $x$ ananassa) by improving root zone temperature. Indian J. Agric. Sci. 2015, 85, 1219-1222.

18. Araghi, A.; Adamowski, J.; Martinez, C.J.; Olesen, J.E. Projections of future soil temperature in northeast Iran. Geoderma 2019, 349, 11-24. [CrossRef]

19. Xia, Z.Q.; Si, L.Y.; Jin, Y.; Fu, Y.F.; Wang, Q.; Lu, H.D. Effects of Root Zone Temperature Increase on Physiological Indexes and Photosynthesis of Different Genotype Maize Seedlings. Russ. J. Plant. Physiol. 2021, 68, 169-178. [CrossRef]

20. Sun, S.J.; Chen, Z.J.; Jiang, H.; Zhang, L.L. Black Film Mulching and Plant Density Influencing Soil Water Temperature Conditions and Maize Root Growth. Vadose Zone J. 2018, 17, 180104. [CrossRef]

21. Hu, Y.J.; Ma, P.H.; Zhang, B.B.; Hill, R.L.; Wu, S.F.; Dong, Q.G.; Chen, G.J. Exploring optimal soil mulching for the wheat-maize cropping system in sub-humid drought-prone regions in China. Agric. Water Manag. 2019, 219, 59-71. [CrossRef]

22. Fu, J.; Sun, N.N.; Liu, T.X.; Yang, Y.L.; Zhao, X.; Li, C.H. Effect of High Temperature Stress on Morphology, Leaf Structure and Grain Yield of Maize. J. Maize Sci. 2019, 27, 46-53.

23. Du, C.F.; Li, C.H.; Liu, T.X.; Zhao, Y.L. Response of anatomical structure and photosynthetic characteristics to low light stress in leaves of different maize genotypes. Acta Ecol. Sinica 2011, 31, 6633-6640.

24. Cai, T.; Meng, X.P.; Liu, X.L.; Liu, T.N.; Wang, H.; Jia, Z.K.; Yang, D.Q.; Ren, X.L. Exogenous Hormonal Application Regulates the Occurrence of Wheat Tillers by Changing Endogenous Hormones. Front. Plant Sci. 2018, 9, 1886. [CrossRef]

25. Sabri, N.S.A.; Zakaria, Z.; Mohamad, S.E.; Jaafar, A.B.; Hara, H. The use of soil cooling for growing temperate crops under tropical climate. Int. J. Environ. Sci. Technol. 2019, 16, 1449-1456. [CrossRef]

26. Cichy, K.A.; Snapp, S.S.; Kirk, W.W. Fusarium root rot incidence and root system architecture in grafted common bean lines. Plant Soil 2017, 300, 233-244. [CrossRef]

27. Agatholleous, E.; Belz, R.G.; Kitao, M.; Koike, T.; Calabrese, E.J. Does the root to shoot ratio show a hormetic response to stress? An ecological and environmental perspective. J. For. Res. 2019, 30, 1569-1580. [CrossRef]

28. Stratopoulos, L.M.F.; Zhang, C.; Haberle, K.H.; Pauleit, S.; Duthweiler, S.; Pretzsch, H.; Rotzer, T. Effects of Drought on the Phenology, Growth, and Morphological Development of Three Urban Tree Species and Cultivars. Sustainability 2019, $11,5117$. [CrossRef]

29. Luo, Y.Z.; Liu, H.; Yan, G.J.; Li, G.; Turner, N.C. Roots of Lucerne Seedlings are More Resilient to a Water Deficit than Leaves or Stems. Agronomy 2019, 9, 123. [CrossRef]

30. Liu, H.S.; Li, F.M.; Xu, H. Deficiency of water can enhance root respiration rate of drought-sensitive but not drought-tolerant spring wheat. Agric. Water Manag. 2004, 64, 41-48. [CrossRef]

31. Zhu, Y.F.; Shi, Z.S.; Lu, D.G.; Wang, Y.T.; Wang, N. Effects of Planting Densities on Basal Stem Vascular Bundles and Root Bleeding Sap of Different Density-tolerant Maize Cultivars. Acta Botan. Boreali Occident. Sin. 2013, 33, 518-526.

32. Zhao, X.; Dong, K.H.; Zhang, Y.; Zhu, H.S.; Yang, W.D.; Yang, M.H. Drought Resistance and Root Anatomy of Lespedeza davurica (Laxm.) Schindl. Acta Agrestia Sin. 2011, 19, 13-19.

33. Srivastava, R.K.; Panda, R.K.; Chakraborty, A.; Halder, D. Enhancing grain yield, biomass and nitrogen use efficiency of maize by varying sowing dates and nitrogen rate under rainfed and irrigated conditions. Field Crop. Res. 2018, 221, 339-349. [CrossRef]

34. Wasaya, A.; Tahir, M.; Ali, H.; Hussain, M.; Yasir, T.A.; Sher, A.; Ijaz, M.; Sattar, A. Influence of varying tillage systems and nitrogen application on crop allometry, chlorophyll contents, biomass production and net returns of maize (Zea mays L.). Soil Tillage Res. 2017, 170, 18-26. [CrossRef]

35. Li, Z.Z.; Zhang, L.; Li, S.; Dong, H.; Wang, Q.Y.; Liu, X.P.; Yao, Y.Q. Responses of stomata and Kranz anatomy of maize leaves to soil water shortages. Chinese J. Appl. Ecol. 2014, 25, 2944-2950.

36. Retta, M.; Ho, Q.T.; Yin, X.Y.; Verboven, P.; Berghuijs, H.N.C.; Struik, P.C.; Nicolai, B.M. A two-dimensional microscale model of gas exchange during photosynthesis in maize (Zea mays L.) leaves. Plant Sci. 2016, 246, 37-51. [CrossRef] [PubMed]

37. Gururani, M.A.; Venkatesh, J.; Tran, L.S.P. Regulation of Photosynthesis during Abiotic Stress-Induced Photoinhibition. Mol. Plant 2015, 8, 1304-1320. [CrossRef] 
38. Wang, H.Q.; Liu, P.; Zhang, J.W.; Zhao, B.; Ren, B.Z. Endogenous Hormones Inhibit Differentiation of Young Ears in Maize (Zea mays L.) Under Heat Stress. Front. Plant Sci. 2020, 11, 533046. [CrossRef]

39. Wu, C.; Cui, K.; Wang, W.; Li, Q.; Fahad, S.; Hu, Q.; Huang, J.L.; Nie, L.X.; Peng, S.B. Heat-induced phytohormone changes are associated with disrupted early reproductive development and reduced yield in rice. Sci. Rep. 2016, 6, 34978. [CrossRef]

40. Duan, N.; Jia, Y.K.; Xu, J.; Chen, H.L.; Sun, P. Research Progress on Plant Endogenous Hormones. Chin. Agric. Sci. Bull. 2015, 31, 159-165.

41. Ren, B.Z.; Hu, J.; Zhang, J.W.; Dong, S.T.; Liu, P.; Zhao, B. Spraying exogenous synthetic cytokinin 6-benzyladenine following the waterlogging improves grain growth of waterlogged maize in the field. J. Agron. Crop Sci. 2019, 205, 616-624. [CrossRef] 